\title{
A INTERAÇÃO ESTRUTURAL ENTRE A DESIGUALDADE DE RAÇA E DE GÊNERO NO BRASIL*
}

\section{José Alcides Figueiredo Santos}

Os princípios de ordenamento social geram conseqüências que vão além dos seus poderes causais específicos. As divisões sociais que organizam desigualdades duráveis exercem efeitos conjuntos derivados da sua interação estrutural. Investiga-se aqui a hipótese de que a desigualdade de gênero de

* Este estudo contou com um auxílio de pesquisa principal da Fundação de Amparo à Pesquisa do Estado de Minas Gerais - Fapemig e um complementar do Conselho Nacional de Desenvolvimento Científico e Tecnológico CNPq. O autor agradece ao professor Trond Petersen, do Departamento de Sociologia da Universidade da Califórnia-Berkeley, pela oportunidade de conhecer seu inovador trabalho metodológico que fundamenta a escolha do modelo estatístico usado nesta investigação. $O$ estudo contou também com a participação de três bolsistas de iniciação cientifica: Lara Cruz Correa, Juliana de Souza Barbosa e Eder Lima Moreira, que colaboraram no manuseio dos dados.

Artigo recebido em junho/2007

Aprovado em fevereiro/2009 renda no Brasil seria afetada pela hierarquia racial. Tendo em vista este fim, assim como as suas motivações teóricas, estima-se a distância (gap) de gênero de renda entre os grupos raciais, usando novas soluções metodológicas, e analisam-se os componentes desta desigualdade no âmbito de cada grupo racial. Este trabalho focaliza as divisões de gênero no interior das divisões de raça, as combinações dessas categorias, considerando a especificidade dos mecanismos de cada divisão social e seus processos de interação social. A análise empreendida situa e explora, de modo complementar, o papel do contexto subjacente da estrutura da desigualdade econômica de classe no entendimento dos padrões de desigualdade emergentes. Esta iniciativa inscreve-se, ainda, em um programa de investigação de maior amplitude a respeito da produção e da reprodução da desigualdade social na sociedade brasileira. ${ }^{1}$ Os estudos já realizados sobre as desigualdades de raça 
e de gênero no Brasil servem de esteio para o tratamento atual das interações entre essas categorias sociais (Figueiredo Santos, 2005a e 2008). ${ }^{2}$

Gênero e raça evoluíram como campos separados de investigação nas ciências sociais. Os estudos raciais privilegiaram o homem não branco e os estudos de gênero, a mulher branca. Esta modalidade de estudo de cada hierarquia separada, em isolamento uma da outra, tanto marginalizou em ambas as áreas o estudo da mulher não branca como incentivou o tratamento meramente aditivo dos atributos de gênero e de raça (Glenn, 2000, pp. 3-4). Não são poucas as pesquisas que, ao considerar gênero e raça como fatores independentes, focalizam um fator em detrimento do outro. Do ponto de vista teórico, omitir gênero ou raça implica assumir que a atribuição de recompensas é neutra em relação ao fator omitido. Em um modelo estatístico, isso representa um erro de especificação, pois se está suprimindo uma variável relevante, correlacionada com variáveis independentes no modelo, o que enviesa as estimativas dos efeitos das variáveis independentes correlacionadas. Já outras pesquisas, quando controlam o outro fator, o que representa avanço, muitas vezes não testam a possibilidade de interações entre ambas as variáveis (Reskin e Charles, 1999, p. 385).

As construções sociais de gênero e raça, embora distintas, estariam entrelaçadas na sua constituição história e na experiência individual. A natureza e a dinâmica do poder, do privilégio e da opressão poderiam ser mais bem entendidas se gênero fosse considerado em combinação com raça, assim como classe. Os papéis de gênero e as experiências de discriminação no local de trabalho podem variar como uma função tanto de gênero como de raça (Ferdman, 1999). Em certo sentido, raça e gênero seriam sistemas de relações sociais mutuamente constituídas, organizadas em torno de diferenças percebidas, e não características de categorias fixas (Glenn, 2000, p. 9). ${ }^{3}$

No estudo das relações entre gênero e raça na produção de desigualdade ganhou curso a tese da "dupla desvantagem", em que a pessoa que ocupa uma posição subordinada em mais de uma hierarquia sofreria da soma das desvantagens de ambas as dimensões. Essa idéia, embora freqüentemente invocada, não tem sido devidamente examinada (Leffler e Xu, 1997, p. 71). A tese da "dupla desvantagem" supõe que os efeitos de gênero e raça são aditivos, de modo que a mulher não branca sofreria a soma da desvantagem plena associada aos dois tipos de status subordinado. Uma revisão da literatura sociológica sobre a interseção de gênero e raça no mercado de trabalho, com foco particular nos Estados Unidos, sugere que a evidência coletada ainda seria mista, sem favorecer claramente uma modalidade de interpretação, e dependeria da questão colocada, do método empregado e do tipo de processo investigado. Apesar da ambigüidade dos resultados empíricos apurados, este artigo argumenta que a focalização da interseção entre ambas as divisões sociais pode enriquecer o entendimento da desigualdade econômica e oferecer conceituações mais acuradas dos processos do mercado de trabalho (Browne e Misra, 2003). A suposição de efeitos aditivos, adotada como orientação ou por motivo de simplicidade, representa, na verdade, uma tese bastante forte, pois supõe que o grupo subordinado enfrenta o ônus integral do pior dos dois mundos. Estudo empírico mais recente apresenta evidências amplas e robustas que colocam em questão a caracterização da "dupla desvantagem" nos Estados Unidos, ao demonstrar que as mulheres de todos os dezoito grupos minoritários estudados sofrem de uma menor penalidade de gênero do que as mulheres brancas, dentro dos respectivos grupos raciais ou étnicos (Greenmam e Xie, 2008).

As investigações da distância (gap) de gênero (ou raça) de renda devem estimar médias ajustadas, não se limitando apenas a comparar médias observadas, pois esse procedimento adicional revela-se importante para demonstrar relações intrínsecas e especificar a natureza dos nexos subjacentes entre as variáveis. Nas análises da distância de gênero de renda no Brasil, que estimam médias ajustadas, predominam trabalhos escritos por economistas na perspectiva da abordagem de "capital humano" (Kassouf, 1998; Matos e Machado, 2006). Este paradigma hegemônico na área e com influências na própria sociologia subestima as bases posicionais e relacionais da desigualdade social, o que não invali$\mathrm{da}$ as contribuições parciais oferecidas e as evidências encontradas, embora algumas delas precisem 
ser qualificadas e mesmo reinterpretadas, em particular quando variáveis posicionais endógenas às divisões sociais são tratadas como se fossem variáveis exógenas, a exemplo da aquisição de credenciais educacionais (Reskin e Charles, 1999, pp. 389-390; Figueiredo Santos, 2002, pp. 199-216 e 253-262). A contribuição sociológica destaca-se particularmente nas investigações sobre a desigualdade racial de recompensas (Valle Silva e Hasenbalg, 1992; Hasenbalg et al., 1999; Telles, 2003). Entretanto, regra geral esses trabalhos não conceituam nem modelam diretamente a possibilidade de efeitos interativos entre ambas as variáveis. Um efeito interativo ocorre quando a associação entre a variável independente de interesse (gênero) e a dependente (renda) difere em força ou forma nos diferentes níveis, ou categorias, da outra variável (raça) com a qual interage. $\mathrm{Na}$ medida em que raça e gênero interagem, excluir um termo de interação do modelo explicativo produz estimativas inexatas dos efeitos de gênero e raça (Reskin e Charles, 1999, p. 386). O presente estudo pretende dar uma contribuição diferenciada em cinco aspectos: a introdução da dimensão da estrutura subjacente da desigualdade econômica de classe na análise das diferenças estimadas; a exploração do entendimento de que raça e gênero representam mecanismos causais distintos, cujas conseqüências para a renda variam em termos da natureza dos nexos causais (diretos ou mediados; tipos de fatores mediadores) e das respectivas intensidades, o que tem importantes implicações para o estudo dos efeitos conjuntos; a modelagem explicativa estrita dos efeitos interativos entre raça e gênero, com o uso de termos multiplicativos entre ambas as variáveis; o uso de uma especificação loglinear de um Modelo Linear Generalizado para estimar as discrepâncias de médias condicionais; e a formulação de uma interpretação teórica da interação estrutural, ou efeitos interativos, entre as divisões de raça e gênero no Brasil.

Os estudos contemporâneos da estratificação social de cor no Brasil demonstraram que em termos de desigualdades de recompensas materiais o contraste marcante se faz entre brancos e não brancos (pardos e pretos). Foram geradas evidências que apontam a existência de um "ciclo cumulativo de desvantagens" que afeta a trajetória e os resultados atingidos pelos não brancos. Esses trabalhos destacam o papel das assimetrias nas trajetórias educacionais e na distribuição da escolaridade entre os grupos raciais nos processos de mobilidade social e de constituição das discrepâncias de rendimento. A desigualdade racial no Brasil, quando comparada aos Estados Unidos, possui como uma de suas características específicas a pequena presença dos não brancos no topo da pirâmide social (Valle Silva e Hasenbalg, 1992; Hasenbalg et al., 1999; Telles, 2003). Estudo das interseções e interações entre classe social e raça no Brasil contribuiu para demonstrar que grande parte da desigualdade racial de renda é uma desigualdade de acesso a contextos e recursos valiosos, notadamente alocação à estrutura de classes, posse de credenciais educacionais e distribuição socioespacial (Figueiredo Santos, 2005a). A distinção analítica entre desigualdade de acesso e desigualdade de tratamento, assim como a correta interpretação do significado de ambas, é uma questão chave para entender a desigualdade racial no Brasil. O elo entre classe social e raça, particularmente forte no Brasil, decorre da importância dos processos de exclusão do controle de recursos que as duas divisões sociais envolvem. Divisões sociais que se cruzam tão fortemente realçam o papel dos efeitos indiretos e dos processos mediadores. As conseqüências das divisões de raça, quando operam mediante a colocação dos não brancos em posições inferiores na hierarquia social, testemunham a importância da raça como uma categoria social que condiciona o acesso desigual aos "bens posicionais" valiosos e em relação aos quais se constituem processos de discriminação de acesso ou alocação.

A desigualdade de gênero no Brasil, como procurei demonstrar em outro artigo conectado ao mesmo programa de investigação, estrutura-se com características bem diferenciadas de raça. Gênero cria uma discrepância de renda observada bem menor do que raça ( $32 \%$ contra $75 \%$ ), entretanto produz uma divergência de renda ajustada ou controlada muito maior (35\% contra $13 \%$ ), o que indica que estamos diante de processos geradores de discrepâncias de renda muito divergentes. Embora exista uma desigualdade de gênero de acesso à estrutura de classes e à ordem ocupacional, as mulheres têm importantes vantagens posicionais particularmente 
nos controles de credenciais educacionais, e o efeito direto de gênero (desigualdade de tratamento) prepondera sobre o efeito indireto (desigualdade de acesso) na explicação das discrepâncias de renda entre homens e mulheres (Figueiredo Santos, 2008). Os processos de seletividade social, cujos efeitos excludentes podem ser cumulativos, e que têm impactos decisivos no controle de "bens posicionais", operam de modo muito mais forte entre as divisões raciais. Embora a maior parte do efeito de raça seja indireta e a maior parte do efeito de gênero seja direta, isso não quer dizer que raça seja menos importante do que gênero. As divisões raciais geram conseqüências mais pronunciadas e excludentes, assim como têm se relevado mais difíceis de serem erodidas no Brasil.

Trabalhos realizados por economistas interessados na temática da discriminação focalizam a comparação entre grupos combinados de raça e gênero: mulheres brancas, mulheres negras, homens brancos e homens negros. Mattos e Machado utilizam cross sections empilhadas para analisar a presença de discriminação por sexo e cor no Brasil. O estudo usa uma técnica de decomposição e define a discriminação na ótica tradicional da teoria de capital humano, como o diferencial de rendimento que não pode ser atribuído às discrepâncias de habilidades (resumidas pelo diferencial de escolaridade). Ao comparar a desigualdade de renda de cor, no âmbito do mesmo sexo, o estudo constata que, além do diferencial associado à discriminação, uma parte significativa, em especial para os homens, deve-se à deficiência na dotação do atributo de qualificação. Já na comparação da desigualdade entre homens e mulheres da mesma cor, o trabalho constata uma redução do diferencial de sexo de rendimentos entre 1987 e 2001, sendo que o que ainda se mantém da desigualdade se deve somente a fatores associados à discriminação. A investigação conclui que "a desigualdade de rendimento do trabalho no Brasil é ainda uma questão de sexo e, sobretudo, de cor" (Matos e Machado, 2006, p. 23). Outro estudo sobre o perfil de discriminação no mercado de trabalho compara os grupos com atributos desvantajosos com os homens brancos, tomados como o grupo padrão, que estabelece a norma no mercado de trabalho. Diversas técnicas são usadas para analisar o diferencial de rendimento devido à discriminação sofrida pelos indivíduos por não serem homens brancos. Constata-se que os homens negros sofrem mais discriminação na formação e na inserção ocupacional, enquanto as mulheres brancas sofrem mais discriminação na definição salarial, quando ambos os grupos são comparados aos homens brancos. O perfil de discriminação das mulheres negras seria "intermediário" entre os homens negros (baseada na formação e inserção) e as mulheres brancas (baseada na definição salarial) (Soares, 2000). Cacciamali e Hirata analisam a discriminação no mercado de trabalho para homens e mulheres, segundo o grupo racial, em dois estados brasileiros com composição racial distinta: Bahia e São Paulo. A investigação compara a probabilidade de obtenção de renda, usado um modelo probit, com o controle de idade e escolaridade, em três categorias que estruturam o mercado de trabalho: dirigentes e gerentes, empregados com carteira de trabalho e empregados sem carteira. Além disso, o trabalho focaliza o grupo diferenciado de trabalhadores pobres, entendidos como aqueles que estão no primeiro quintil da distribuição da renda média familiar per capita. Contata-se que a discriminação de gênero predomina na categoria de dirigentes e gerentes; no entanto, as probabilidades de obtenção de renda de homens e mulheres não brancos, independentemente do nível de escolaridade, são inferiores àquelas dos brancos. No grupo de empregado com registro prevalece a discriminação de gênero, enquanto no de empregado sem registro destaca-se a discriminação racial. Entre os pobres, existe discriminação de gênero, porém a discriminação racial não apresenta significância estatística (Cacciamali e Hirata, 2005).

Examinar gênero e raça simultaneamente pode oferecer um quadro relevante das situações específicas dos vários subgrupos formados das combinações dessas categorias (Leffler e Xu, 1997, p. 73). Entretanto, ao se fazer isso, perdem-se as demarcações entre as divisões de raça e de gênero, que representam mecanismos causais distintos e cujas conseqüências para a renda se fazem sentir através de características e elos explicativos diferenciados. A mulher negra no Brasil, por ser mulher e negra, tende a estar em maior desvantagem, mesmo que não 
exista uma "soma simples" das duas desvantagens. Entretanto, ao se realizar a superposição de raça e gênero, como conseqüência torna-se difícil precisar a contribuição independente de cada "componente" responsável por esta grande desvantagem, das co-variáveis associadas a cada um, assim como dos fatores que permitem entender os efeitos conjuntos, o que pode ser especialmente problemático diante da existência de processos claramente divergentes entre as duas divisões sociais. Em face das divergências constatadas entre gênero e raça na desvantagem de renda bruta e de renda ajustada, que têm relação com a predominância dos efeitos indiretos na desigualdade racial e dos efeitos diretos na desigualdade de gênero, seria melhor trilhar um percurso analítico que distingue e especifica os efeitos aditivos, diretos e indiretos, e os interativos, que são efeitos sobre efeitos, em vez de tomar como ponto de partida a fusão das duas categorias.

Estudos sociológicos mais recentes que abordam os efeitos conjuntos de gênero e de raça na produção de desigualdade de recompensas realizam comparações relevantes e reveladoras, porém não chegam a modelar diretamente, com o uso de termos multiplicativos, os efeitos interativos que especificam as condições segundo as quais os efeitos de uma variável de interesse se altera em força ou forma a depender do nível ou categoria da outra variável com a qual interage. Uma investigação sobre a relação entre o desenvolvimento regional desigual, confrontando os estados de São Paulo e Bahia, e a desigualdade salarial de raça e gênero no Brasil, mostrou que em 1991 a maior distância de gênero se encontrava entre os brancos. Ao usar um modelo tradicional de decomposição da distância de renda, em que a discriminação representa o "resíduo" não explicado pelas dotações de capital humano, o estudo chega à conclusão já preconfigurada pelo modelo adotado de que a mulher branca seria o "grupo que sofre a maior discriminação salarial” (Lovell, 2000, p. 291). Estudo mais recente focaliza explicitamente a articulação e a tematização cruzada dos determinantes de gênero e de natureza étnico-racial. A decomposição do diferencial de salários revela que as mulheres brancas sofrem mais da discriminação gerada no interior do mercado de trabalho. Os homens negros são mais penalizados pela desigualdade de acesso às credenciais educacionais. Entre as posições mais elevadas no mercado de trabalho, no entanto, prevalece também para os homens negros o componente de discriminação. Já entre as mulheres negras um caleidoscópio de fatores de acesso e de discriminação direta explicam a distância salarial em relação aos homens brancos. O grau de discriminação é crescente conforme se caminha para o topo da hierarquia de renda e isso prevalece para todos os grupos subordinados (Bidernam e Guimarães, 2004).

Persiste ainda um conhecimento empírico limitado das discrepâncias de recompensas que emergem das interações entre gênero e raça. Como se não bastasse esta limitação, o tratamento das interações entre raça e gênero tem se realizado muitas vezes de modo passivo, como se as evidências de efeitos interativos representassem basicamente nuanças empíricas. Não tem sido feita uma tentativa de derivar significado teórico para os padrões interativos encontrados. Entretanto, os efeitos interativos entre raça e gênero possuem informação de interesse teórico que deve ser abordada de modo direto e ativo (Greenmam e Xie, 2008, p. 1219). O presente estudo insere-se em um programa de investigação abrangente das principais divisões sociais no país, notadamente classe, raça e gênero, com uma unidade ou convergência de orientações teóricas, instrumentos de mensuração, base de dados e estratégias de análise. Os resultados obtidos pela investigação prévia das características específicas das divisões categóricas de raça e gênero contribuem para clarificar os termos de comparação entre as categorias, esclarecem as divergências de processos e conseqüências, assim como oferecem uma oportunidade especial para abordar os efeitos interativos entre ambas as divisões sociais.

Pretende-se colocar à prova a proposição de que a desigualdade de gênero no Brasil não seria homogênea entre os grupos raciais. Uma especificação adequada dos processos causais nos estudos da desigualdade de gênero envolve a incorporação das interações entre raça e gênero, de modo que o desenho da investigação permita que o efeito de gênero possa diferir entre os grupos raciais, evitando-se a suposição de que a desigualdade de gênero seria equivalente entre brancos e não brancos (Reskin 
e Charles, 1999, pp. 385-386). As explicações da desigualdade entre homens e mulheres não podem ser generalizadas automaticamente para brancos e não brancos. Foi escolhido o recorte racial dicotômico entre brancos e não brancos (pardos e pretos), pois se encontra aí o divisor preponderante da desigualdade racial de renda no Brasil (Valle Silva, 2000, pp. 18-19; Telles, 2003, p. 192).

Este estudo adota uma abordagem sociológica que privilegia os determinantes relacionais, categóricos e estruturais na geração de desigualdades de recompensas. Não se adota aqui a solução tradicional de estimar resíduos da análise de regressão, após o controle dos fatores de capital humano, como medidas do conceito de discriminação. Essa prática revela limitações em particular quando se pretende comparar duas dimensões distintas da desigualdade, como são raça e gênero, cada qual com os seus próprios determinantes estruturais. Esse tipo de abordagem tradicional, ao constatar que as diferenças de gênero de rendimentos, ajustadas por capital humano, são maiores que aquelas de raça, estimula a conclusão artificial de que a discriminação de gênero suplantaria a discriminação racial. Tal conclusão representa basicamente um resultado construído pelos próprios termos em que a questão é posta. A lógica subjacente a essa abordagem alimenta a prática teórica e empiricamente pouco consistente de tratar variáveis endógenas como se fossem exógenas. As variáveis estipuladas supostamente como exógenas às divisões sociais podem responder estatisticamente por uma parte substancial das diferenças de rendimentos do trabalho, em particular no caso de raça. Os indicadores de capital humano e social, no entanto, devem ser tratados tanto como resultados como causas da desigualdade racial e de gênero. Eles estão inextricavelmente associados ao papel que raça e gênero tem tido e continuam a ter como princípios fundamentais de organização da vida social (Marini, 1989, pp. 361 362; Reskin e Charles, 1999, pp. 389-393).

No tratamento das interações entre gênero e raça, com a construção de termos multiplicativos, manteremos o foco na desigualdade de gênero, tendo em vista o argumento teórico que será desenvolvido. Sem desconhecer a natureza simétrica dos efeitos interativos, pretende-se estimar a variação racial do "efeito de gênero". Essa abordagem possui a virtude de mensurar a magnitude e a significância estatística do efeito condicional, ou seja, o montante da distância de gênero de renda em cada grupo racial. Entretanto, possui a limitação de não realizar uma comparação direta entre, por exemplo, o homem branco e a mulher não branca, ou entre quaisquer dois grupos que difiram um do outro tanto em raça como em gênero (Greenmam e Xie, 2008, p. 1218). Por outro lado, ao se considerar os grupos que contrastam em ambas as dimensões, confundem-se os mecanismos e os resultados característicos de cada divisão social e perde-se a distinção da desigualdade de gênero, que foi o "ângulo" escolhido para olhar as interações entre gênero e raça.

Este estudo pretende abordar igualmente, como um passo preliminar, a desigualdade de alocação ou acesso à estrutura de classes dos grupos combinados de gênero e raça. A estrutura social marca um padrão de desigualdade entre as posições de classe. Parte importante das discrepâncias entre estes grupos combinados pode ser mediada pelo acesso aos contextos de classe que são desigualmente recompensados. O contexto subjacente da estrutura da desigualdade econômica de classe ajuda a situar e entender os componentes de alocação subjacentes às discrepâncias de gênero de renda entre os grupos raciais.

\section{Distribuição dos grupos e acesso à estrutura de classes}

A Tabela 1 retrata os padrões de distribuição e acesso desproporcional de homens e mulheres, diferenciados por grupo racial, à estrutura de posições de classe no Brasil. A distribuição percentual de gênero entre as categorias de classe permite desde já identificar uma relação, ou associação, entre as duas variáveis e mostrar o quanto gênero condiciona o acesso à ordem de classe. Entretanto, a comparação entre os grupos será realizada recorrendo à noção de chances (odds) e ao cálculo das razões entre chances (odds ratio) ou chances relativas. Uma chance representa a razão entre a freqüência de estar em uma categoria e a freqüência de não estar nesta categoria. Isto equivale a comparar duas probabilidades formando a razão entre as probabilidades. O resul- 
tado pode ser interpretado como a chance de um indivíduo selecionado ao acaso na população ser encontrado na categoria de interesse em vez de em outra categoria. $\mathrm{Na}$ análise de dados categóricos, o "efeito" de uma variável na outra é mais bem expresso em termos de chances relativas, que corresponde à razão entre duas chances. A chance de uma categoria pode ser comparada com qualquer outra. Comparam-se nesta tabela apenas as discrepâncias de gênero de chances em cada universo racial distinto. Esta medida que permite comparar as chances, ou mensurar as chances relativas, possui uma interpretação simples. Quando as chances das duas categorias comparadas são iguais, o razão resultará no valor 1 (um), o que equivale à inexistência de associação estatística. Valores menores que 1 (um) implicam em uma associação negativa, e maiores que 1 (um), em uma associação positiva. Quanto mais o valor se distanciar de 1 (um) maior será a associação (Reynolds, 1982; Rudas, 1998). Na Tabela 1 o homem (branco ou não branco) forma o numerador das razões entre chances.
No universo do grupo branco, os homens possuem uma vantagem de gênero de acesso a todas as posições que implicam em controle de ativos de capital e de terra. Esta vantagem cresce conforme aumenta a dimensão do capital controlado. $\mathrm{Na}$ área agrícola, onde predominam relações de gênero mais tradicionais, a chance masculina de ser o titular de uma pequena atividade agrícola é multiplicada por 4,45 em comparação à feminina.

Entre as localizações privilegiadas de classe média existe no grupo branco uma forte desvantagem masculina no acesso à condição de empregado especialista, um quase equilíbrio à posição de especialista autônomo e uma pequena vantagem à posição de autoridade exercida pelo gerente. Ao olhar o conjunto da configuração de classe média no universo branco, os homens ostentam uma desvantagem de acesso, devido ao peso relativo ou densidade maior do emprego de especialista - o que pode ser visto comparando as percentagens nas colunas - e ao fato de as chances relativas da mulher serem pronunciadamente maiores nesta categoria.

Tabela 1

Distribuição Percentual dos Grupos Combinados de Gênero e de Raça entre as Categorias de Classe e Discrepâncias de Gênero nas Chances Relativas de Acesso à Categoria, conforme o Grupo Racial-Brasil, 2005

\begin{tabular}{lcccccc}
\hline Categorias de classe & $\begin{array}{c}\text { Homem } \\
\text { branco }\end{array}$ & $\begin{array}{r}\text { Mulher } \\
\text { branca }\end{array}$ & $\begin{array}{c}\text { Chances } \\
\text { relativas de } \\
\text { gênero }\end{array}$ & $\begin{array}{c}\text { Homem } \\
\text { não branco }\end{array}$ & $\begin{array}{c}\text { Mulher } \\
\text { não branca }\end{array}$ & $\begin{array}{c}\text { Chances } \\
\text { relativas de } \\
\text { gênero }\end{array}$ \\
\hline Capitalista & 1,24 & 0,59 & 2,11 & 0,20 & 0,08 & 2,50 \\
Pequeno empregador & 6,40 & 3,36 & 1,97 & 3,14 & 1,49 & 2,14 \\
Autônomo com ativos & 9,42 & 5,47 & 1,79 & 7,56 & 4,19 & 1,87 \\
Autônomo agrícola & 6,90 & 1,11 & 4,45 & 9,59 & 2,36 & 4,39 \\
Especialista autônomo & 1,66 & 1,64 & 1,02 & 0,40 & 0,36 & 1,11 \\
Gerente & 3,95 & 3,59 & 1,10 & 1,70 & 1,50 & 1,14 \\
Empregado especialista & 4,26 & 6,80 & 0,62 & 1,39 & 2,51 & 0,55 \\
Empregado qualificado & 6,76 & 11,59 & 0,55 & 4,21 & 8,62 & 0,47 \\
Supervisor & 2,54 & 1,09 & 2,37 & 2,26 & 0,65 & 3,54 \\
Trabalhador típico & 37,26 & 35,27 & 1,09 & 35,47 & 29,63 & 1,31 \\
Trabalhador elementar & 10,32 & 4,23 & 2,61 & 21,26 & 7,97 & 3,12 \\
Autônomo precário & 8,47 & 10,16 & 0,82 & 11,63 & 13,89 & 0,82 \\
Empregado doméstico & 0,78 & 15,1 & 0,04 & 1,18 & 26,74 & 0,03 \\
Total & 100,00 & 100,00 & - & 100,00 & 100,00 & - \\
\hline
\end{tabular}

Fonte: IBGE, 2006 (tabulações especiais, ver Quadro 1 do Anexo). Dados para os casos com renda positiva. 
Entre as posições ambíguas de classe de empregados qualificados e supervisores, as associações se fazem em direções opostas. As chances de acesso aumentam significativamente entre os supervisores e regridem fortemente entre os empregados qualificados. O quadro registrado na última categoria reflete $\mathrm{o}$ avanço educacional das mulheres e o forte contingente de professoras de primeiro grau presentes nesta posição.

Ao voltar o olhar para a base da estrutura de classes, constata-se que os homens brancos têm chances relativas maiores, embora não muito maiores, de estarem no grande agregado de trabalhadores típicos. Entre as posições de classe destituídas, logo abaixo na Tabela 1, a chances masculinas suplantam bastante as chances femininas de serem encontradas entre as ocupações mais braçais tanto agrícolas como não agrícolas que compõem os trabalhadores elementares. Por outro lado, os homens possuem uma vantagem de gênero de estarem negativamente associados às posições de autônomos precários e empregados domésticos, que obtêm menores recompensas.

Não serão comentadas aqui as discrepâncias de alocação entre os grupos raciais, que podem ser facilmente constatadas comparando as colunas de percentagens, pois isso foi objeto de outro estudo (Figueiredo Santos, 2005a). Tendo em vista o foco do presente estudo nas variações raciais da desigualdade de gênero, a Tabela 1 serve para mensurar o componente de desigualdade de gênero de acesso às posições de classe desigualmente recompensadas que podem estar subjacentes às discrepâncias de gênero de renda e às possíveis divergências neste hiato de renda quando são confrontados os grupos raciais.

Quando são comparados o universo branco e o universo não branco percebem-se semelhanças e divergências nos padrões de interseções ou cruzamentos entre classe e gênero. Os homens não brancos possuem maiores vantagens relativas no acesso a ativos de capital, e estas vantagens crescem igualmente conforme aumenta a dimensão do capital controlado.

Entre os não brancos o exercício de autoridade representa uma prerrogativa de acesso masculina mais forte, em particular na posição de primeira linha de supervisão. Já na dimensão de controle de ativos de qualificação, exceto entre os especialistas autônomos, ser homem no universo não branco implica em associação fortemente negativa com as posições que incorporam qualificação e perícia entre os empregados.

Entre a classe trabalhadora assalariada vincula$\mathrm{da}$ às formas coletivas de trabalho, que exerce um trabalho típico ou elementar, os homens não brancos possuem fortes vantagens de gênero de acesso quando confrontados às mulheres do mesmo grupo racial. Já entre as posições de classe destituídas que são autônomas ou estão inseridas no âmbito domiciliar, as chances relativas de gênero mostramse bastantes semelhantes em ambos os universos raciais. A distribuição racial entre estas posições, cabe observar, é extremamente divergente: os não brancos estão muito mais concentrados entre os trabalhadores elementares e os empregados domésticos. Entretanto, a análise realizada aqui focaliza as discrepâncias de gênero dentro de cada grupo racial. As razões entre chances cumprem bem este objetivo, pois representam medidas de associação que buscam captar relações inerentes entre as variáveis, ou seja, as relações intrínsecas que independem das divergências entre as distribuições marginais das variáveis contrastadas.

\section{Distâncias de gênero de renda entre os grupos raciais}

A Tabela 2 apresenta dados sobre as diferenças de renda média em reais entre as interseções ou cruzamentos das categorias sociais de interesse, tendo em vista a necessidade de situar o papel mediador da estrutura de classes no entendimento da variação racial das discrepâncias de gênero de renda. A última linha dessa tabela, onde está o total, revela que a vantagem masculina de renda, não ajustada por outras variáveis, é maior entre os brancos $(46,14 \%)$ do que entre os não brancos $(38,55 \%)$. Além disso, observa-se que na verdade existem diferentes patamares de vantagem masculina, a depender do contexto de classe, o que testemunha o papel não apenas mediador, mas também moderador da estrutura de classes. O papel mediador decor- 
re do acesso diferenciado às posições que são desigualmente recompensadas. $\mathrm{O}$ papel moderador de classe mostra-se através do fato de que a distância de gênero de renda se acentua ou se atenua a depender do contexto de classe, conforme demonstrado em outro artigo (Figueiredo Santos, 2008). Caberia então observar se o distanciamento da média geral, ou seja, a sua variação entre os contextos de classe, seria semelhante ou não entre os grupos raciais, particularmente entre as categorias de classe que possuem uma densidade maior na estru- tura de classes e por isso possuem um peso maior na formação da média do grupo racial. O resultado não mostra um contraste marcante. Entre os brancos e não brancos iguais números de contextos de classe (seis) e quase os mesmos contextos, exceto um, puxam a média da discrepância de gênero de renda para cima. Os dados sinalizam, então, uma importância maior da desigualdade de gênero de acesso à ordem de classe como um fator a ser considerado no entendimento das variações raciais da discrepância de gênero de renda.

Tabela 2

Renda Média Mensal em Real do Trabalho Principal e Vantagem do Homem, conforme os Cruzamentos entre Categorias de Classe, Gênero e Grupo Racial - Brasil, 2005

\begin{tabular}{lrrrrrr}
\hline Categorias de classe & $\begin{array}{c}\text { Homem } \\
\text { branco }\end{array}$ & $\begin{array}{r}\text { Mulher } \\
\text { branca }\end{array}$ & $\begin{array}{r}\text { Vantagem } \\
\text { masculina }\end{array}$ & $\begin{array}{r}\text { Homem } \\
\text { não branco }\end{array}$ & $\begin{array}{r}\text { Mulher } \\
\text { não branca }\end{array}$ & $\begin{array}{c}\text { Vantagem } \\
\text { masculina }\end{array}$ \\
\hline Capitalista & $5.684,48$ & $3.675,03$ & 54,68 & $4.349,61$ & $2.704,48$ & 60,83 \\
Pequeno empregador & $2.241,81$ & $1.813,54$ & 23,61 & $1.400,37$ & $1.320,12$ & 6,08 \\
Autônomo com ativos & $1.198,54$ & 720,67 & 66,31 & 703,93 & 503,94 & 39,68 \\
Autônomo agrícola & 520,47 & 276,35 & 88,34 & 271,90 & 130,72 & 108,00 \\
Especialista autônomo & $3.667,54$ & $2.549,22$ & 43,87 & $2.327,66$ & $1.836,91$ & 26,72 \\
Gerente & $2.646,62$ & $1.777,94$ & 48,86 & $1.588,15$ & $1.198,65$ & 32,49 \\
Empregado especialista & $2.948,97$ & $2.002,98$ & 47,23 & $2.101,80$ & $1.391,38$ & 41,06 \\
Empregado qualificado & $1.300,27$ & 906,94 & 43,37 & 966,77 & 672,98 & 43,66 \\
Supervisor & $1.169,46$ & $1.061,37$ & 10,18 & 931,20 & 782,11 & 19,06 \\
Trabalhador típico & 707,48 & 553,57 & 27,80 & 572,78 & 431,24 & 32,82 \\
Trabalhador elementar & 374,27 & 351,03 & 6,62 & 314,34 & 307,46 & 2,24 \\
Autônomo precário & 602,28 & 347,95 & 73,09 & 427,80 & 231,83 & 84,53 \\
Empregado doméstico & 393,67 & 284,60 & 38,32 & 334,52 & 252,54 & 32,46 \\
Total & $1.128,13$ & 771,95 & 46,14 & 582,94 & 420,73 & 38,55 \\
\hline
\end{tabular}

Fonte: IBGE, 2006 (tabulações especiais, ver Quadro 1 do Anexo). Dados para os casos com renda positiva.

\section{Método de análise e modelo estatístico}

Passa-se agora à especificação do método de análise dos dados e das características do modelo estatístico usado para estimar a distância (gap) de renda ajustada. O confronto simples de rendas médias, ainda que relevante, pois mostra a distância bruta de renda entre as categorias, não permite demonstrar sem ambigüidades o "efeito de gênero", uma vez que a renda está associada também a ou- tras variáveis, que cabe controlar, para ver a variabilidade da renda que decorre do fator de interesse. Além disso, a aplicação de um modelo estatístico incorpora à análise as múltiplas variáveis que atuam no interior do nexo original constatado. Esse processo de elaboração da relação original permite abordar e trazer à superfície a estrutura subjacente dos dados. A análise da variação da desigualdade de gênero de renda no Brasil, entre os grupos raciais, será realizada estimando-se a distância de 
gênero em sucessivos Modelos Lineares Generalizados, que incluem outros fatores com impacto importante na renda e que podem estar associados às divisões de gênero e de raça. O uso destes "experimentos estatísticos" permite conhecer os principais fatores que conformam, especificam e medeiam a desigualdade de gênero, assim como estabelecer os efeitos diretos, não mediados, das divisões de gênero entre os grupos raciais.

A presente investigação beneficia-se de uma nova proposição metodológica formulada pelo professor Trond Petersen, da Universidade da Califórnia-Berkeley, para a estimativa da média condicional de uma variável dependente intervalar, como a renda. Essa solução retém a vantagem interpretativa de estimar diferenças relativas de rendimentos médios, porém sem os problemas associados à especificação semilogarítmica de um modelo de regressão padrão. Uma especificação loglinear de um Modelo Linear Generalizado produz interpretações de diferenças relativas, em termos de médias aritméticas, em vez de médias geométricas, ao contrário do que ocorre com a especificação semilogarítmica do modelo de regressão OLS, após o cálculo do exponencial do coeficiente estimado, visando à sua reconversão para a métrica original da variável dependente intervalar (Petersen, 2006; Goodman 2006). O Modelo Linear Generalizado têm três componentes: um aleatório, um sistemático e um de ligação. O primeiro refere-se à variável dependente e à distribuição de probabilidade que está associada a ela. O componente sistemático diz respeito às variáveis independentes e como elas se combinam com a finalidade de construir um modelo explicativo. O de ligação especifica como a média da variável dependente está relacionada com o chamado preditor linear (o modelo explicativo). A média pode ser modelada diretamente ou alguma função monotônica da média pode ser então modelada (Agresti, 2007, pp. 66-67; Jaccard, 2001, pp. 3-4). ${ }^{4}$ O presente estudo utilizará o Modelo Linear Generalizado com uma função de ligação logarítmica e uma distribuição Gamma. Na especificação loglinear deste Modelo a transformação logarítmica é internalizada dentro do próprio modelo. A função de ligação exponencializa o preditor linear em vez de fazer a transformação logarítmica da variável dependente. Já a distribuição Gamma é apropriada para lidar com variáveis dependentes positivas com coeficiente de variação constante - propriedade que compartilha com a distribuição log-normal -, mas o modelo é robusto mesmo na presença de grandes desvios deste critério. Modelar observações com uma distribuição Gamma e uma função de ligação logarítmica é uma alternativa melhor do que usar a regressão padrão com a transformação logarítmica da variável dependente, pois o modelo não requer nenhuma transformação externa, retém as observações originais e é mais fácil de interpretar. "De fato", explicam Hardin e Hilbe, "porque o formato dos dois parâmetros da distribuição gamma é flexível e pode ser parametrizado para ajustar muitos formatos de resposta, ele seria preferível ao modelo Gaussiano para muitas situações de dados com respostas estritamente positivas" (Hardin e Hilbe, 2007, p. 90; Halekoh, 2007). Todos os Modelos formam estimados, usando o programa estatístico Stata, versão 9.2 (Stata, 2005).

A medida apropriada da distância de renda entre categorias contrastadas depende do propósito da análise. A distância de renda estimada aqui reflete diversas formas de discriminação, não apenas aquelas que ocorrem no âmbito da inserção no mundo do trabalho, mas também as conseqüências decorrentes de escolhas e trajetórias empreendidas sob a influência de constrangimentos vividos ou antecipados (Gunderson, 1989, pp. 48-49). Os coeficientes da especificação loglinear, ao fornecerem diferenças relativas entre as categorias, ajustam-se bem à lógica teórica do estudo da desigualdade. Esta especificação, além disso, ajuda a corrigir a forte assimetria positiva da distribuição e contribui para reduzir a influência na estimativa dos valores extremos dissonantes do conjunto.

$\mathrm{Na}$ especificação da equação de rendimentos para estimar a distância de gênero, o tratamento das horas trabalhadas joga um papel bastante importante. Segue-se aqui a especificação proposta pelo inovador trabalho metodológico de Morgan e Arthur, que evita a subestimação do gap de gênero de renda. Recomenda-se o uso do log do rendimento como variável dependente e do log do tempo trabalhado como variável independente de controle, com o retorno para o equivalente em $\log$ das horas 
trabalhadas variando de modo seccional (piecewise), em uma função spline, através do espectro de horas trabalhadas (Morgan e Arthur, 2005, pp. 398-401). $\mathrm{O}$ equivalente da primeira recomendação em um Modelo Linear Generalizado seria a escolha da função de ligação logarítmica.

A comparação entre grupos envolvendo o controle de múltiplas variáveis, visando a estudar efeitos interativos ou condicionais, às vezes é feita por meio do cálculo de equações de regressão para cada grupo em separado. Entretanto, essa prática analítica usualmente não resulta num teste estatístico de diferenças nos coeficientes estimados entre os dois grupos, quando este teste é necessário caso se queira falar de diferenças entre os grupos. A análise conduzida com a construção de termos interativos, aplicada aqui, realiza esta avaliação estatística das diferenças entre grupos (Jaccard e Turrisi, 2003, p. 36). No modelo interativo, a variável independente $\mathrm{X}$ possui um efeito condicional, que depende do valor da variável $Z$, com a qual interage. Estima-se o efeito de X em Y, dado $\mathrm{Z}=0$ (zero). Quando são construídos termos interativos entre variáveis binárias, como gênero e raça, o efeito condicional ao valor 0 (zero) refere-se naturalmente à categoria de referência (omitida) da outra variável que compõe o termo interativo (Brambor, Clark e Golder, 2006, pp. 73-74). A análise das variações da distância de gênero entre os grupos raciais utilizará a estratégia de "recodificação das variáveis binárias", em que são realizados sucessivos recálculos da equação de regressão e produzidas as estatísticas relevantes após a especificação de cada categoria de referência de interesse (Jaccard e Turrisi, 2003, pp. 55-60).

A pesquisa empírica utiliza a base de microdados da PNAD de 2005 (IBGE, 2006). A amostra utilizada neste estudo é composta de 165.147 casos, que possuem informações válidas para todas as variáveis. Devido à escolha da especificação loglinear de um Modelo Linear Generalizado, a análise foi restrita aos casos com renda positiva. Utiliza-se apenas a renda do trabalho principal, por motivo de ajuste, já que a classificação socioeconômica usada para mensurar o conceito de classe social foi construída com base no trabalho principal da pessoa.

\section{Variações da distância de gênero entre os grupos raciais}

A Tabela 3 apresenta os resultados dos modelos estimados já convertidos em diferenças percentuais a favor do homem ${ }^{5}$. O modelo 1, composto apenas das variáveis do termo interativo, mostra que a vantagem de gênero dos homens não é homogênea entre os grupos raciais. A distância de gênero entre os brancos suplanta a registrada entre os não brancos. Este padrão revelador de uma maior penalidade de gênero para as mulheres brancas será mantido em todos os modelos, com variações de intensidade.

O modelo 2 controla as diferenças de horas trabalhadas entre homens e mulheres recorrendo a uma solução que evita a subestimação da distância de gênero, conforme foi demonstrado em outro artigo (Figueiredo Santos, 2008). A desigualdade existente de horas trabalhadas entre homens e mulheres, ainda assim, faz com que a distância de gênero seja reduzida em ambos os grupos raciais. Entretanto, a distância se reduz mais entre os não brancos, mostrando que neste grupo existe uma maior divergência de gênero no efeito das horas trabalhadas, conforme captado pela spline linear, o que gera um aumento da discrepância de gênero entre os dois universos raciais.

O modelo 3 introduz o controle das credenciais educacionais. Controlam-se neste modelo os efeitos da desigualdade de educação entre os grupos e dos diferenciais de renda por nível educacional. $\mathrm{Na}$ especificação do modelo de regressão sem termos interativos entre a credencial educacional e o fator atribuído raça ou gênero, os diferenciais de renda por nível educacional seriam equivalentes entre os grupos. Isso significa que o efeito produzido na distância de renda decorre, dados os diferenciais existentes de renda por nível educacional, da desigualdade de educação encontrada entre as categorias. Esse procedimento produz e revela um incremento muito significativo da desigualdade de tratamento de gênero nos grupos raciais. $\mathrm{O}$ aumento absoluto ainda mais forte da distância entre os brancos faz com que a discrepância racial na desigualdade de gênero atinja aí o seu ponto mais alto. Como a distância de renda já está em um patamar muito 
Tabela 3

\section{Distância (gap) de Renda do Trabalho Principal a favor do Homem, em relação à Mulher, no Grupo Branco e Não Branco e Diferença entre Ambos, Estimada por meio de Modelo Linear Generalizado - Brasil, 2005}

\begin{tabular}{|c|c|c|c|}
\hline Modelo & $\begin{array}{c}\text { Distância } \\
\text { entre brancos } \\
(\%)\end{array}$ & $\begin{array}{c}\text { Distância } \\
\text { entre não } \\
\text { brancos (\%) }\end{array}$ & $\begin{array}{c}\text { Diferença } \\
(\mathrm{B}-\mathrm{NB}) \\
(\%)\end{array}$ \\
\hline 1 (gênero, raça e termo interativo) & 45,99 & 38,44 & 7,55 \\
\hline 2 (+ horas de trabalho: spline linear)* & 37,73 & 28,66 & 9,07 \\
\hline 3 (+ educação) & 58,58 & 44,36 & 14,22 \\
\hline 4 (+ tempo de trabalho e tempo no trabalho atual) & 47,83 & 37,58 & 10,25 \\
\hline 5 (+ região, residência urbana e migrante) & 50,45 & 42,24 & 8,21 \\
\hline 6 (+ setor público e seis grandes setores econômicos) & 48,98 & 39,72 & 9,26 \\
\hline 7 (+ categorias de classe $)$ & 38,50 & 31,94 & 6,56 \\
\hline 8 (+ composição de gênero das ocupações) & 30,63 & 23,82 & 6,80 \\
\hline
\end{tabular}

Notas: Modelo Linear Generalizado, usando a distribuição Gamma e a função de ligação log. * Spline linear do equivalente em log dos intervalos de horas de trabalho (ver Quadro 2 do Anexo). O impacto percentual dos coeficientes foi calculado conforme: 100 [exp (Coef.) - 1]. Todos os coeficientes originais são estatisticamente significativos no nível de 0,001 ou mais. Fonte: Tabelas 1-A e 2-A do Anexo Estatístico.

elevado entre os brancos, o controle estatístico das credenciais educacionais - o controle de um fator que faz emergir o efeito direto da desigualdade de tratamento de gênero - incrementa a variação absoluta da distância de gênero entre os grupos raciais, embora o seu aumento relativo, em comparação ao percentual registrado no modelo anterior, mostre uma divergência muito pequena entre os grupos raciais. $^{6}$

O controle das discrepâncias de tempo de trabalho e tempo no trabalho atual, realizado no modelo 4, em que as mulheres brancas e não brancas possuem desvantagens, reduz a diferença entre as duas distâncias, mas essa defasagem ainda se mantém em um patamar alto. De uma maneira muito simplificada pode-se dizer que o controle da variabilidade devido a uma desvantagem diminui a distância de renda entre o grupo em desvantagem (mulher) e o privilegiado (homem), revelando-se, desse modo, o peso da contribuição deste componente da distância de gênero de renda. Nesse sentido as discrepâncias de gênero em relação a estes fatores parecem ser maiores entre os brancos, pois ocorre aí a maior retração tanto absoluta como relativa da distância de gênero.

Os controles das circunstâncias de localização geográfica, moradia urbana e de condição de migração, realizados no modelo 5, aumentam as distâncias de gênero em ambos os grupos raciais, porém esse processo ocorre com mais força no grupo não branco, o que precipita uma redução da sua variação racial. Esse resultado mostra que a distribuição regional e urbana dá uma pequena vantagem relativa à mulher no grupo não branco, quando confrontada ao homem não branco, pois o seu controle estatístico faz com que aumente mais a distância de gênero neste grupo racial.

A partir do modelo 6 são introduzidas variáveis socioeconômicas relacionadas com a divisão social do trabalho e que são de natureza tipicamente estruturais. O modelo 6 faz com que volte a crescer a divergência na distância de gênero. A desigualdade de gênero de acesso aos setores econômicos, nos quais existem diferentes padrões de renda média, 
revela-se maior entre os não brancos, pois o controle deste componente mediador da desigualdade gera uma redução maior da distância de gênero de renda neste grupo racial, o que produz o incremento da sua discrepância entre os grupos raciais.

A introdução das categorias de classe, no modelo 7, reduz a discrepância entre as distâncias de gênero ao seu nível mais baixo. Isso significa que o acesso assimétrico às posições de classe, que são desigualmente recompensadas, joga um papel chave na explicação da divergência existente. Cabe primeiro descortinar o tipo de distância de renda que passou a ser estimada neste modelo. Controla-se agora a distribuição diferenciada de homens e mulheres entre as posições de classe, dentro de cada universo racial, e as discrepâncias de remuneração entre as posições de classe. A desigualdade de acesso à ordem de classe entre homens e mulheres parece ser maior no universo branco, pois o controle das interseções entre classe e gênero em cada grupo racial aproxima mais as distâncias de gênero de renda entre brancos e não brancos, devido ao fato de a distância de gênero cair mais no grupo branco, tanto no nível absoluto como relativo. O forte componente de acesso desigual a recursos valiosos, que está associado à opressão racial, responde possivelmente por uma menor diferenciação de classe entre mulheres e homens não brancos.

Por fim, o modelo 8 incorpora um indicador de segregação ocupacional de gênero, que é a proporção de mulheres em cada um dos 519 grupos ocupacionais da PNAD. O controle da segregação ocupacional de gênero existente no interior das categorias de classe social - a alocação entre as posições de classe já foi controlada estatisticamente no modelo anterior - tem um grande impacto na distância de gênero, porém aumenta apenas ligeiramente a sua divergência entre os grupos raciais. Note-se então que a divergência entre os grupos raciais está mais associada aos grandes agregados da estrutura de classes, já que o componente interno de segregação ocupacional, apesar da sua importância como fator mediador da desigualdade de gênero nos dois grupos raciais, responde apenas por uma tênue desvantagem relativa da mulher não branca, indicada pelo fato da vantagem masculina diminuir mais no grupo não branco.

\section{Método alternativo: o efeito contido no termo interativo}

Uma metodologia alternativa para analisar e apresentar os efeitos interativos entre gênero e raça nos rendimentos foi proposta e utilizada por Emily Greenmam e Yu Xie (2008). Após fazer uma revisão crítica da tese da "dupla desvantagem" na literatura norte-americana, assim como das estratégias desenvolvidas para estudar os efeitos conjuntos de raça e gênero, o trabalho oferece um modelo de investigação empírica, usando o que seria, na formulação das autoras, uma conceituação nova e menos restritiva dos seus efeitos. Nesta abordagem, o coeficiente de interesse principal na equação de regressão é aquele formado pelo termo de interação entre as variáveis raça e gênero. Para entender adequadamente o significado do valor captado pelo termo interativo, cabe atentar para o fato de este não representar estritamente a magnitude de um efeito, como são os coeficientes das variáveis que o compõem, mas expressar essencialmente como um efeito muda, ou seja, ele corresponde a um efeito sobre um efeito (Kam e Franzese, 2007). O estudo desenvolvido aqui tem relação estreita com esta metodologia, diferindo mais na forma de apresentação dos dados, pois a variação racial do coeficiente de gênero entre os grupos raciais decorre justamente da magnitude e do sinal (positivo ou negativo) do termo interativo, que estima como o efeito de raça muda o efeito de gênero ou, simetricamente, como o efeito de gênero muda o efeito de raça. ${ }^{7}$

No modelo interativo construído aqui para aplicar este método alternativo, raça é incluída como variável binária que assume o valor 1 para o branco. Gênero é incluído como uma variável binária que recebe o valor 1 para o homem. Gerou-se, então, um termo interativo ou multiplicativo entre a variável raça e gênero. O coeficiente do termo interativo representa a extensão em que ser membro do grupo racial branco tem um efeito diferente para o homem em comparação à mulher ou, alternativamente, a extensão em que ser homem tem um efeito diferente para membros do grupo branco em relação aos membros do grupo não branco. $\mathrm{O}$ exponencial ou antilog do coeficiente do termo interativo, na codificação adotada aqui, pode ser pensado como a taxa 
de rendimento observado/predito ou esperado do homem branco, em que o rendimento predito é baseado na suposição de efeitos apenas aditivos (ausência de interação) entre as variáveis raça e gênero. O Modelo Linear Generalizado usado neste estudo exponencializa o preditor linear. As pesquisadoras norteamericanas usam um modelo de regressão padrão com a transformação logarítmica dos rendimentos. Um valor positivo do coeficiente corresponde ao exponencial maior que 1 , enquanto o valor negativo corresponde a um valor menor que 1 (Greenam e Xie, 2008). O exponencial do coeficiente no valor de 1 equivale à ausência de interação entre as variáveis, ou seja, o coeficiente de raça não afeta o de gênero e vice-versa. Esta forma de apresentação tem o mérito de realçar o significado do termo de interação, de um modo matemático simples e claro, como uma discrepância positiva ou negativa em relação ao valor 1 (um) neutro, que traduz ausência de interação.

A Tabela 4 apresenta o exponencial do coeficiente estimado do termo interativo, que dá a taxa de rendimento observado em relação ao predito para o homem branco. Os valores do exponencial do coeficiente, nos diversos modelos estatísticos, indicam que os rendimentos médios do homem branco variam de 5,0\% (modelo 7) a 9,9\% (modelo 3) a mais do que seria predito sob a suposição de relações apenas aditivas entre as variáveis raça e gênero. A discrepância entre o rendimento observado e predito do homem branco mostra que este se beneficia de um ganho adicional de gênero em comparação ao homem não branco.

Tabela 4

Taxa de Rendimento Observado/Predito do Homem Branco, em relação à Suposição de Efeitos apenas Aditivos entre Raça e Gênero (=1,00) - Brasil, 2005.

\section{Modelo}

Taxa de rendimento observado/predito (homem branco)*

1 (gênero, raça e termo interativo)

1,0545

2 (+ horas de trabalho: spline linear)**

1,0705

3 (+ educação)

1,0986

4 (+ tempo de trabalho e tempo no trabalho atual)

1,0745

5 (+ região, residência urbana e migrante)

1,0577

6 ( + setor público e seis grandes setores econômicos)

1,0663

7 (+ categorias de classe)

1,0497

8 (+ composição de gênero das ocupações)

Notas: Modelo Linear Generalizado, usando a distribuição Gamma e a função de ligação log. Todos os coeficientes originais são estatisticamente significativos ao nível de 0,001 ou mais.

*Exponencial do coeficiente do termo interativo entre raça e gênero.

** Spline linear do equivalente em log dos intervalos de horas de trabalho

Fonte: Tabela 2-A do Anexo Estatístico.

Greenmam e Xie (2008) constataram a existência na sociedade norte-americana de uma maior penalidade de gênero para a mulher branca, quando comparada a todos os outros grupos raciais e étnicos. $\mathrm{Na}$ interpretação deste resultado, recorreram ao enfoque de especialização de papéis, baseado na economia neoclássica, cujo modelo teórico vincula a desigualdade no trabalho à desigualdade de gênero na família. As autoras encontraram alguma evidência que sugere que nas famílias brancas existiria uma maior especialização de papel do que nas famílias de outros grupos raciais. Isso significa que a 
mulher branca nos Estados Unidos, na ótica desta abordagem de especialização de papéis, possuiria uma maior penalidade de gênero na sua renda individual, pois o contexto familiar particularmente dos casais brancos com filhos, diferente daquele da mulher não branca, indicaria uma "racionalidade econômica" derivada desta vantagem de grupo, associada à especialização de papéis entre homens e mulheres, dentro da divisão de trabalho e do compartilhamento de renda familiar, ainda que a mulher tenha nesta especialização uma função individual subalternizada no mercado de trabalho. A convergência metodológica entre os dois estudos, no entanto, não impede a existência de uma importante divergência teórica na interpretação dos resultados obtidos, apesar de as evidências apresentadas por ambos os artigos contradizerem os pressupostos aditivos inerentes à proposição da dupla desvantagem. $\mathrm{O}$ presente artigo, ao se debruçar sobre os dados brasileiros, inscreve-se em uma orientação sociológica situada dentro da tradição marxista em ciências sociais e adota uma linha de interpretação distinta.

\section{Significado teórico da interação entre gênero e raça}

A noção de limitação estrutural ajuda a clarificar o aparente paradoxo subjacente à menor penalidade de gênero sofrida por um grupo racialmente privilegiado, que ocorre como conseqüência dos processos de interação entre os determinantes sociais. Erik Olin Wright introduziu a noção de "modo de determinação" com a finalidade de enfatizar a pluralidade de causas dentro da teoria marxista. A limitação estrutural seria, então, um modo de determinação em que uma estrutura ou processo estabelece limites de variação em outra estrutura ou processo (Wright, 1980 e 1981). A interpretação dos resultados encontrados destaca a forma assumida pelo processo de interação estrutural entre as hierarquias sociais e as características da desigualdade racial no Brasil. Em primeiro lugar, deve-se entender que a hipótese da "dupla desvantagem" reflete uma visão "estanque" da estruturação da desigualdade, pois pressupõe que a desigualdade em uma hierarquia não gera conseqüências para a desigualdade na outra hierarquia. A pessoa em posição subordinada nas duas hierarquias sofreria, então, o efeito integral somado de ambas as desigualdades. A relação não aditiva ou interativa supõe a possibilidade de uma hierarquia social condicionar o efeito da outra hierarquia: interação equivale justamente a um efeito sobre outro efeito. A forma deste condicionamento pode ser pensada como um constrangimento da assimetria passível de ser produzida pela outra hierarquia. Em segundo lugar, no Brasil existe uma disparidade racial de renda muito elevada, como pode ser constatado na distância racial bruta. Da mesma forma, homens e mulheres não brancos sofrem de um elevadíssimo componente de desigualdade de acesso a contextos e recursos valiosos, que caracteriza a desigualdade de raça no Brasil. Esta opressão racial tão acentuada seria capaz de tolher, em certa medida, a variação que pode ser produzida por outros atributos, como gênero, no interior do grupo não branco, subordinado na dimensão racial. Processo semelhante foi constatado no estudo das interações entre classe e raça no Brasil, que demonstrou a existência de uma menor desigualdade de classe entre os não brancos, em relação aos brancos. A interação estrutural entre classe e raça assume um sentido especialmente restritivo quando a exploração de classe comum limita a desigualdade racial dentro da classe trabalhadora e, de modo especial, no seu segmento mais destituído (Figueiredo Santos, 2005a). Quando são controladas as diferenças de recursos e contextos valiosos, que estão no cerne da desigualdade racial brasileira, a variação racial entre as distâncias de gênero de renda recua para um patamar menor. A explicação, no Brasil, da maior vantagem de gênero do homem branco, equivalente à menor vantagem do homem não branco, se radicaria nas características da desigualdade racial. $O$ peso da opressão racial comum de mulheres e homens não brancos deixaria um espaço menor para a realização da assimetria causal associada ao atributo de gênero. A hierarquia racial estabeleceria certo limite de variação à hierarquia de gênero. Parte principal do efeito de raça na discrepância de gênero é mediada pela alocação desigual dos grupos raciais na estrutura de classes. A variação racial da distância de gênero de renda, 
como foi demonstrada, atinge o seu menor montante $(6,56 \%)$ quando ocorre o controle estatístico das categorias de classe social. A estrutura subjacente da desigualdade econômica de classe revela-se um importante fator mediador na constituição dos padrões que emergem das interações entre raça e gênero.

Em um quadro geral de alta vantagem de gênero a favor dos homens, a menor penalidade de gênero sofrida pelas mulheres não brancas, por conta de uma certa compressão social introduzida pela opressão racial, não deve obscurecer o fato de estas mulheres experimentarem uma forte desigualdade de acesso aos contextos de classe desigualmente recompensados. A dimensão de perícia e qualificação permitiu avanços de classe para a mulher no seu mundo racial de não brancos. Entretanto, a vantagem obtida pelas mulheres não brancas, em relação aos homens da mesma cor, no acesso às posições privilegiadas de classe média, mostra-se contraditada por uma forte distribuição relativa entre as posições mais destituídas, que possuem uma densidade social muito maior. Entre as mulheres não brancas, deve-se lembrar, a divisão racial permanece ainda como uma barreira bem mais difícil de ser transposta do que a desigualdade de gênero. $\mathrm{Na}$ verdade, todos os não brancos (homens e mulheres) estão em clara desvantagem na ordem de classe.

\section{Notas}

1 Tal programa explora os efeitos das divisões de classe, raça e gênero, assim como de suas interseções e interações, na produção da desigualdade. Utiliza-se como instrumento analítico uma classificação socioeconômica para o Brasil que aperfeiçoa a tipologia utilizada no livro Estrutura de posições de classe no Brasil (Figueiredo Santos, 2002). Os fundamentos teóricos das suas categorias empíricas foram formulados em outro artigo (Figueiredo Santos, 2005b).

2 Considerando o percurso já trilhado e o interesse atual pelas relações condicionais entre essas categorias, não será repetido aqui o posicionamento teórico dessas noções sociológicas. A recapitulação de manifestações empíricas de desigualdade organizadas no Brasil em torno dessas categorias ocorrerá apenas quando houver necessidade.
3 Não se assume neste trabalho a tese de que gênero seria inerentemente constituído por raça. Exploram-se aqui os efeitos da interação entre essas categorias.

4 A transformação logarítmica, de amplo uso, faz parte da família de transformações monotônicas que preserva a ordem subjacente da variável transformada.

5 Embora o interesse principal deste estudo esteja na estimativa dos coeficientes parciais que captam os efeitos interativos, a Tabela 1-A do Anexo Estatístico fornece a estatística BIC, usada para comparação de modelos. O modelo com melhor ajuste é aquele que registra o menor valor. Como esta estatística freqüentemente possui um valor negativo, o modelo com o maior valor negativo seria preferível (Hardin e Hilbe, 2007, pp. 56-58).

6 Na mudança do modelo 2 para o modelo 3, ocorre entre os brancos um maior aumento absoluto da discrepância percentual, de $20,85 \%$, contra $15,70 \%$ entre os não brancos, o que explica a ampliação da divergência racial. Entretanto, o aumento relativo da distância de renda, em relação ao patamar anterior, difere muito pouco entre os grupos raciais. Entre os não brancos a distância é multiplicada por 1,548, ao passar de $28,66 \%$ para 44,36\%; já a distância entre os brancos é multiplicada por 1,553 , ao passar de $37,73 \%$ para $54,58 \%$. A vantagem feminina no controle de credenciais educacionais, dentro do respectivo grupo racial, é maior entre os não brancos quando computada em termos de médias de anos completos de estudo. A mulher não branca possui em média 7,565 contra 5,999 anos de escolaridade do homem, o que dá uma vantagem de 1,566 anos; já a mulher branca têm em média 9,538, contra 8,154 anos do homem, o que gera uma vantagem de 1,414 (dados para as pessoas com posição de classe e renda positiva).

7 O trabalho de Greenmam e Xie apresenta uma instrutiva representação e demonstração matemática da divergência entre os efeitos aditivos e interativos. As autoras modelam os efeitos interativos pela introdução de termos interativos na equação de regressão. A convergência entre as abordagens fica clara, por exemplo, quando elas sintetizam a metodologia para examinar a relação entre a determinação dos rendimentos de raça e de gênero: "Para cada grupo racial ou étnico k, nós computamos a quantidade d, que representa a diferença entre a distância de renda de gênero da minoria e dos brancos" (Greenam e Xie, 2008, p. 1225). 


\section{BIBLIOGRAFIA}

AGRESTI, Alan. (2007), An introduction to categorical data analysis. 2 ed. Hoboken, John Wiley \& Sons.

BRANBOR, Thomas; CLARK, William Roberts \& GOLDER, Matt. (2006), "Understanding interaction models: improving empirical analysis". Political Analysis, 14 (3): 63-82.

BIDERMAN, Ciro \& GUIMARÃES, Nadya Araújo. (2004), "Na ante-sala da discriminação: o preço dos atributos de sexo e cor no Brasil (1989-1999)". Estudos Feministas, 12 (2): 177-200.

BROWNE, Irene \& MISRA, Joya. (2003), “The intersection of gender and race in the labor market". Annual Review of Sociology, 29: 487-513.

CACCIAMALI, Maria Cristina \& HIRATA, Guilherme Issamu. (2005), "A influência da raça e do gênero nas oportunidades de obtenção de renda: uma análise da discriminação em mercados de trabalho distintos: Bahia e São Paulo". Estudos Econômicos, 35 (4): 767-795.

FIGUEIREDO SANTOS, José Alcides. (2002), Estrutura de posições de classe no Brasil: mapeamento, mudancas e efeitos na renda. Belo Horizonte/Rio de Janeiro, Editora UFMG/Iuperj.

. (2005a), "Efeitos de classe na desigualdade racial no Brasil". Dados-Revista de Ciências Sociais, 48 (1): 21-65.

. (2005b), "Uma classificação sócioeconômica para o Brasil". Revista Brasileira de Ciências Sociais, 20 (58): 27-49.

. (2008), "Classe social e desigualdade de gênero no Brasil". Dados - Revista de Ciências Sociais, 51 (2): 353-402.

FERDMAN, Bernardo M. (1999), "The color and culture of gender in organizations: attending to race and ethnicity, in Gary N. Powell (ed.), Handbook of gender and work. Thousand Oaks, Sage.

GLENN, Evelyn Nakano. (2000), "The social construction and institutionalization of gender and race, in Myra Marx Ferree, Judith Lorber, Beth B. Hess (ed.). (2000), Revisioning gender, Walnut Creek, Altamira Press.

GOODMAN, Leo. (2006), "A new way to view the magnitude of the difference between the arithmetic mean and the geometric mean, and the difference between the slopes when a con- tinuous dependent variable is expressed in raw form versus logged form". Working paper, University of California, Berkeley, Departamento de Sociologia e Departamento de Estatística.

GREENMAM, Emily \& XIE, Yu. (2008), "Double Jeopardy? The interaction of gender and race on earnings in the United States". Social Forces, 86 (3): 1217-1244.

GUNDERSON, Mortley. (1989), "Male-female wage differentials and policy responses". Journal of Economic Literature, 27 (1): 46-72.

HALEKOH, Ulrich. (2007), "Gamma distributed data: course in generalized linear modeling with biological applications". Disponível no site $<$ http:/ /gbi.agrsci.dk/statistics/courses/phd08/>.

HARDIN, James W. \& HILBE, Joseph M. (2007), Generalized linear models and extensions. $2 \mathrm{ed}$. College Station, Stata Press.

HASENBALG, Carlos; VALLE SILVA, Nelson do \& LIMA, Márcia. (1999), Cor e estratificação social. Rio de Janeiro, Contra Capa.

IBGE. (2006), "Pesquisa nacional por amostra de domicílios - 2005”. Microdados. Rio de Janeiro, IBGE.

JACCARD, James. (2001), Interaction effects in logistic regression. Thousand Oaks, Sage.

JACCARD, James \& TURRISI, Robert. (2003), Interaction effects in multiple regression. 2 ed. Thousand Oaks, Sage.

KASSOUL, Ana Lúcia. (1998), "Wage gender discrimination and segmentation in the Brazlian labor market". Economia Aplicada, 2 (2).

KAM, Cindy \& FRANZESE JR., Robert J. (2007), Modeling and interpreting interactive bypotheses in regression analysis: a refresher and some practical advice. Michigan, Michigan Press.

LEFFLER, Ann \& XU, Wu. (1997), “Gender and race impacts on occupational segregation, prestige, and earnings, in Paula J. Dubek e Kathryn Borman (eds.), Women and work: a reader, New Brunswick, Rutgers University Press.

LOVELL, Peggy A. (2000), "Race, gender and regional labor market inequalities in Brazil". Review of Social Economy, LVIII (3): 279-93.

MARINI, Margaret Mooney. (1989), "Sex differences in earnings in The United States". Annual Review of Sociology, 15: 343-380. 
MATOS, Raquel Silvério \& MACHADO, Ana Flávia. (2006), "Diferencial de rendimento por cor e sexo no Brasil (1987-2001)". Econômica, 8 (1): 5-27, Rio de Janeiro.

MORGAN, Laurie A. \& ARTHUR, Michelle M. (2005), "Methodological consideration in estimating the gender pay gap for employed professionals". Sociological Methods \& Research, 33 (3): 383-403.

PETERSEN, Trond. (2006), "Functional form for continuous dependent variables: raw versus logged form”. Working Paper, University of California, Berkeley, Departamento de Sociologia.

RESKIN, Barbara F. \& CHARLES, Camille Z. (1999), "Now you see'em, now don't: race, ethnicity, and gender in labor market research", in Irene Browne (ed.), Latinas and African American women at work: race, gender and economic inequality. Nova York, Russell Sage Fundation.

REYNOLDS, H. T. (1982), Analysis of nominal data. Beverly Hills, Sage.
RUDAS, Ramás. (1998), Odds ratios in the analysis of contingecy tables. Thousand Oaks, Sage.

SOARES, Sergei Saurez Dillon. (2000), "O perfil da discriminação no mercado de trabalho: homens negros, mulheres brancas e mulheres negras". Texto para Discussão n. 769, Brasília, Ipea.

STATA. (2005), Stata base reference manual. Release 9, vols. 1-3. College Station, Stata Press.

TELLES, Edward. (2003), Racismo à brasileira: uma nova perspectiva sociológica. Rio de Janeiro, Relume Dumará.

VALLE SILVA, Nelson do. (2000), "A research note on the cost of not being white in Brazil". Studies in Comparative International Development, 35 (2): 18-27.

VALLE SILVA, Nelson do. \& HASENBALG, Carlos. (1992), Relações raciais no Brasil contemporâneo. Rio de Janeiro, Rio Fundo.

WRIGHT, Erik Olin. (1980), "Class and occupation". Theory and Society, 9: 177-214. . (1981), Classe, crise e Estado. Rio de Janeiro, Jorge Zahar.

\section{Anexos}

\section{Quadro 1}

Classificação Socioeconômica para o Brasil: Categorias Empíricas e Critérios Operacionais

\section{Categorias}

Capitalista e fazendeiro

\section{Critérios operacionais}

Posição na ocupação de empregador; empregador não agrícola com 11 ou mais empregados; empregador agrícola com 11 ou mais empregados permanentes; empregador agrícola que emprega simultaneamente 6 ou mais empregados permanentes e 11 ou mais empregados temporários; empregador agrícola com 1.000 hectares ou mais de terra, independentemente do número de empregados.
Posição na ocupação de empregador; empregador não agrícola que ocupa de 1 a 10 empregados; empregador agrícola que ocupa de 1 a 10 empregados permanentes, desde que não empregue simultaneamente de 6 a 10 empregados permanentes e 11 ou mais empregados temporários.
Autônomo com ativos
Posição na ocupação de conta-própria com atividade de natureza não agrícola, cujo empreendimento ou titular possui uma ou mais das seguintes condições: estabelecimento (loja, oficina, fábrica, escritório, banca de jornal ou quiosque), veículo automotor (taxi, caminhão, van etc.) usado para trabalhar ou ocupação qualificada no emprego principal. 


\section{Categorias Critérios operacionais}

Autônomo agrícola

Posição na ocupação de conta-própria com atividade em empreendimento do ramo que compreende a agricultura, silvicultura, pecuária, extração vegetal, pesca e piscicultura.

Especialista autônomo Posição na ocupação de conta-própria ou empregador; especialista de acordo com o grupo ocupacional, com até 5 empregados ou sem empregados, com ou sem estabelecimento (loja, oficina, fábrica, escritório).

Gerente

Posição na ocupação de empregado, gerente de acordo com o grupo ocupacional, abarcando os diretores de empresas, dirigentes da administração pública, administradores em organizações de interesse público (sem fins lucrativos etc.) e gerentes de produção, operações e de áreas de apoio.

Empregado especialista

Posição na ocupação de empregado, especialista de acordo com o grupo ocupacional, incluindo as profissões credenciadas, as profissões de menor poder profissional e os professores do ensino médio e profissional com formação superior.

Empregado qualificado Posição na ocupação de empregado, empregado qualificado de acordo com o grupo ocupacional, abarcando os técnicos de nível médio nas diversas áreas, professores no ensino infantil e fundamental, professores de nível médio no ensino profissional, professores em educação física e educação especial.

Supervisor Posição na ocupação de empregado, supervisor, chefe, mestre ou contramestre de acordo com o grupo ocupacional.

Trabalhador típico

Posição na ocupação de empregado, trabalhador em reparação e manutenção mecânica, ferramenteiro e operador de centro de usinagem; trabalhador de semirotina na operação de instalações químicas, petroquímicas e de geração e distribuição de energia; trabalhador de semi-rotina em serviços administrativos, comércio e vendas; trabalhador de rotina na operação de máquinas e montagem na indústria; trabalhador de rotina em serviços administrativos, comércio e vendas.

Trabalhador elementar Posição na ocupação de empregado, trabalhador com tarefas de trabalho bastante elementares na indústria e nos serviços, como ajudantes de obras, trabalhadores elementares na manutenção de vias públicas, faxineiros, lixeiros e carregadores de carga; trabalhadores manuais agrícolas, garimpeiros e salineiros, exclusive os trabalhadores na mecanização agrícola, florestal e drenagem.

Autônomo precário

Posição na ocupação de conta-própria e empreendimento ou titular sem a posse de nenhuma das seguintes condições: estabelecimento (loja, oficina, fábrica, escritório, banca de jornal ou quiosque), veiculo automotor (taxi, caminhão, van, etc) usado para o trabalho ou ocupação qualificada no emprego principal.

Empregado doméstico

Posição na ocupação de trabalhador doméstico, com ou sem carteira de trabalho assinada. 


\section{Quadro 2}

Relação e Descrição das Variáveis Utilizadas no Estudo

\begin{tabular}{ll} 
Variáveis & Descrição \\
\hline Renda & Variável dependente intervalar. Rendimento mensal do trabalho principal; considera-se ren- \\
& dimento mensal do trabalho a remuneração bruta mensal para empregados e trabalhadores \\
& domésticos e a retirada mensal para conta própria e empregadores; no caso de renda variável, \\
& valor médio mensal (média condicional estimativa com o uso de uma função de ligação \\
& logarítmica).
\end{tabular}

Raça

Variáveis binárias. Não-branco (pardo e preto) como categoria designada, código 1; branco como categoria de referência, código 0 (recodificação da variável para efeito de estimação).

Raça* gênero

Variáveis binárias. Termos multiplicativos (interativos) entre as variáveis binárias de raça e de gênero.

Gênero

Variável binária. Masculino como categoria designada, código 1; feminino como categoria de referência, código 0 .

Horas de trabalho

Spline linear do equivalente em log das faixas de horas de trabalho semanal estipuladas: 1 a 29 horas, 30 a 39 horas, 40 a 49 horas e 50 horas ou mais de trabalho.

Educação

Variáveis Binárias. De 8 a 10 anos escolaridade completa, 11 a 14 anos, 15 anos ou mais, como categorias designadas, código 1; menos de oito anos, como categoria de referência, código 0 .

Anos de trabalho

Variável intervalar, idade menos a idade em que começou a trabalhar.

Anos de trabalho ${ }^{2}$

Variável intervalar, quadrado dos anos de trabalho.

Anos no trabalho atua

Variável intervalar, número de anos no trabalho principal atual, com valores a partir de 0 (menos de 1 ano).

Anos no trabalho atual ${ }^{3} \quad$ Variável contínua, quadrado dos anos no trabalho principal atual.

Região

Variáveis binárias. Regiões Sudeste, Sul, Centro-Oeste como categorias designadas, código 1; Nordeste como categoria de referência, código 0.

Residência

Variável binária. Residência urbana como categoria designada, código 1; residência rural como categoria de referência, código 0 .

Migração

Variável binária. Pessoa nascida em outro município que não o município de residência, como categoria designada, código 1; pessoa nascida no município de residência, como categoria de referência, código 0 . 


\section{Variáveis Descrição}

Setor público/privado

Variável binária. Setor público federal, estadual ou municipal, abrangendo, além da administração direta, as suas fundações, autarquias e empresas públicas e de economia mista, como categoria designada, código 1; setor privado como categoria de referência, código 0 .

Setores econômicos

Variáveis binárias. Indústria de transformação, indústria extrativa, serviços produtivos, serviços de distribuição e serviços sociais como categorias designadas, código 1; serviços pessoais como categoria de referência, código 0 .

Classe

Variáveis binárias. Capitalista, pequeno empregador, auto-empregado especialista, autônomo com ativos, autônomo agrícola, empregado especialista, gerente, empregado qualificado, supervisor, trabalhador, autônomo precário, empregado doméstico, como categorias designadas, código 1; trabalhador elementar como categoria de referência, código 0 .

Composição de gênero das Variável intervalar. Proporção de mulheres nos grupos ocupacionais, estimada ao nível do ocupações código ocupacional de quatro dígitos da Classificação Brasileira de Ocupações (CBO) - Domiciliar.

\section{Anexo estatístico}

Tabela 1-A

Modelos Lineares Generalizados Sucessivamente Abrangentes e os Coeficientes Estimados (Variável "Masculino” Estima a Vantagem de Renda do Homem Branco)

\begin{tabular}{|c|c|c|c|c|c|c|c|c|}
\hline Variáveis & Modelo 1 & Modelo 2 & Modelo 3 & Modelo 4 & Modelo 5 & Modelo 6 & Modelo 7 & Modelo 8 \\
\hline (Constante) & $\begin{array}{c}6,651979 \\
(0,081851)\end{array}$ & $\begin{array}{c}5,248531 \\
(0,0399687)\end{array}$ & $\begin{array}{c}4,586146 \\
(0,0316376)\end{array}$ & $\begin{array}{c}4,019993 \\
(0,0287026)\end{array}$ & $\begin{array}{c}3,447754 \\
(0,0294978)\end{array}$ & $\begin{array}{c}3,475021 \\
(0,0305)\end{array}$ & $\begin{array}{l}3,448256 \\
(0,02512)\end{array}$ & $\begin{array}{c}3,589045 \\
(0,0258834)\end{array}$ \\
\hline Masculino & $\begin{array}{l}0,3783923 \\
(0,010714)\end{array}$ & $\begin{array}{c}0,3201629 \\
(0,0108237)\end{array}$ & $\begin{array}{c}0,4611216 \\
(0,0083757)\end{array}$ & $\begin{array}{c}0,3908807 \\
(0,0073801)\end{array}$ & $\begin{array}{l}0,4084319 \\
(0,007305)\end{array}$ & $\begin{array}{c}0,3986873 \\
(0,0075898)\end{array}$ & $\begin{array}{c}0,3256627 \\
(0,0059236)\end{array}$ & $\begin{array}{c}0,2671944 \\
(0,0064765)\end{array}$ \\
\hline Não branco & $\begin{array}{c}-06089287 \\
(0,0121463)\end{array}$ & $\begin{array}{l}-0,5840133 \\
(0,0120818)\end{array}$ & $\begin{array}{l}-0,2666641 \\
(0,0094006)\end{array}$ & $\begin{array}{l}-0,2347689 \\
(0,008242)\end{array}$ & $\begin{array}{l}-0,1657172 \\
(0,0083664\end{array}$ & $\begin{array}{l}-0,1559473 \\
(0,0084693)\end{array}$ & $\begin{array}{l}-0,0949376 \\
(0,0065364)\end{array}$ & $\begin{array}{c}-0,0939382 \\
(0,0065187)\end{array}$ \\
\hline $\begin{array}{l}\text { Masculino* } \\
\text { não branco }\end{array}$ & $\begin{array}{c}-0,053115 \\
(0,01564)\end{array}$ & $\begin{array}{c}-0,681164 \\
(0,0155498)\end{array}$ & $\begin{array}{c}-0,940038 \\
(0,0119492)\end{array}$ & $\begin{array}{l}-0,0718759 \\
(0,0104712)\end{array}$ & $\begin{array}{r}-0,0560688 \\
(0,0103553\end{array}$ & $\begin{array}{r}-0,0642068 \\
(0,010486)\end{array}$ & $\begin{array}{l}-0,0484684 \\
(0,0080944)\end{array}$ & $\begin{array}{l}-0,0535507 \\
(0,0080793)\end{array}$ \\
\hline Lghs1a 29 & & $\begin{array}{c}0,3584113 \\
(0,0130076)\end{array}$ & $\begin{array}{c}0,3029849 \\
(0,0102611)\end{array}$ & $\begin{array}{c}0,2800173 \\
(0,0091029)\end{array}$ & $\begin{array}{c}0,2885807 \\
(0,0090535)\end{array}$ & $\begin{array}{c}0,2756825 \\
(0,0092011)\end{array}$ & $\begin{array}{c}0,2789534 \\
(0,0070954)\end{array}$ & $\begin{array}{l}0,2805371 \\
(0,007077)\end{array}$ \\
\hline Lghs30a 39 & & $\begin{array}{c}1,226938 \\
(0,0434348)\end{array}$ & $\begin{array}{c}1,115506 \\
(0,033873)\end{array}$ & $\begin{array}{c}1,13522 \\
(0,0298655)\end{array}$ & $\begin{array}{c}0,9506609 \\
(0,0296674\end{array}$ & $\begin{array}{c}0,9373989 \\
(0,0302363)\end{array}$ & $\begin{array}{c}0,9235307 \\
(0,0236776)\end{array}$ & $\begin{array}{c}0,9051451 \\
(0,0236352)\end{array}$ \\
\hline
\end{tabular}




\begin{tabular}{|c|c|c|c|c|c|c|c|c|}
\hline Variáveis & Modelo 1 & Modelo 2 & Modelo 3 & Modelo 4 & Modelo 5 & Modelo 6 & Modelo 7 & Modelo 8 \\
\hline Lghs 40 a 49 & & $\begin{array}{c}-0,9358351 \\
(0,052835)\end{array}$ & $\begin{array}{l}0,1314242 \\
(0,041585)\end{array}$ & $\begin{array}{c}0,2166261 \\
(0,0366624)\end{array}$ & $\begin{array}{c}0,2464361 \\
(0,0362038)\end{array}$ & $\begin{array}{l}0,3606677 \\
(0,037092)\end{array}$ & $\begin{array}{c}0,2412049 \\
(0,0285867)\end{array}$ & $\begin{array}{c}0,2319894 \\
(0,0285377)\end{array}$ \\
\hline Lghs 50 mais & & $\begin{array}{c}0,9331086 \\
(0,0502138)\end{array}$ & $\begin{array}{l}0,8660062 \\
(0,038326)\end{array}$ & $\begin{array}{c}0,6400849 \\
(0,0334895)\end{array}$ & $\begin{array}{c}0,6470467 \\
(0,0332366)\end{array}$ & $\begin{array}{c}0,6480801 \\
(0,0336854)\end{array}$ & $\begin{array}{l}0,3287646 \\
(0,0259205)\end{array}$ & $\begin{array}{c}0,3246168 \\
(0,0258847)\end{array}$ \\
\hline Edu 8 a 10 & & & $\begin{array}{c}0,2662266 \\
(0,0083669)\end{array}$ & $\begin{array}{c}0,3845195 \\
(0,0075241)\end{array}$ & $\begin{array}{c}0,3243878 \\
(0,0075215)\end{array}$ & $\begin{array}{c}0,2908467 \\
(0,0076503)\end{array}$ & $\begin{array}{l}0,2000492 \\
(0,005965)\end{array}$ & $\begin{array}{c}0,2038998 \\
(0,0059552)\end{array}$ \\
\hline Edu 11a 14 & & & $\begin{array}{c}0,7189483 \\
(0,0070888)\end{array}$ & $\begin{array}{c}0,8165396 \\
(0,0064956)\end{array}$ & $\begin{array}{c}0,7620926 \\
(0,0065701)\end{array}$ & $\begin{array}{c}0,6940263 \\
(0,0069373)\end{array}$ & $\begin{array}{c}0,467339 \\
(0,0056982)\end{array}$ & $\begin{array}{c}0,4789453 \\
(0,0057123)\end{array}$ \\
\hline Edu 15 & & & $\begin{array}{c}1,734368 \\
(0,0111648)\end{array}$ & $\begin{array}{c}1,724387 \\
(0,0099635)\end{array}$ & $\begin{array}{c}1,65557 \\
(0,0099874)\end{array}$ & $\begin{array}{c}1,564196 \\
(0,010759)\end{array}$ & $\begin{array}{c}0,9987002 \\
(0,0098912)\end{array}$ & $\begin{array}{c}1,016037 \\
(0,0098897)\end{array}$ \\
\hline $\begin{array}{l}\text { Anos de } \\
\text { trabalho }\end{array}$ & & & & $\begin{array}{r}0,031848 \\
(0,0006105)\end{array}$ & $\begin{array}{c}0,0288534 \\
(0,0006065)\end{array}$ & $\begin{array}{l}0,0282887 \\
(0,000612)\end{array}$ & $\begin{array}{c}0,0263513 \\
(0,0004728)\end{array}$ & $\begin{array}{c}0,0258964 \\
(0,0004723)\end{array}$ \\
\hline $\begin{array}{l}\text { Anos de } \\
\text { trabalho }^{2}\end{array}$ & & & & $\begin{array}{l}-0,0004042 \\
(0,0000109)\end{array}$ & $\begin{array}{l}-0,0003811 \\
(0,0000107)\end{array}$ & $\begin{array}{l}-0,0003684 \\
(0,0000108)\end{array}$ & $\begin{array}{l}-0,0003843 \\
(0,0000083)\end{array}$ & $\begin{array}{l}-0,0003761 \\
(0,0000083)\end{array}$ \\
\hline $\begin{array}{l}\text { Anos no atual } \\
\text { emprego }\end{array}$ & & & & $\begin{array}{c}0,0307715 \\
(0,0007269)\end{array}$ & $\begin{array}{c}0,0317581 \\
(0,0007163)\end{array}$ & $\begin{array}{c}0,0305262 \\
(0,0007295)\end{array}$ & $\begin{array}{l}0,0245379 \\
(0,000572)\end{array}$ & $\begin{array}{c}0,0243713 \\
(0,0005713)\end{array}$ \\
\hline $\begin{array}{l}\text { Anos no atual } \\
\text { emprego }^{2}\end{array}$ & & & & $\begin{array}{l}-0,0005226 \\
(0,0000191)\end{array}$ & $\begin{array}{l}-0,0004688 \\
(0,0000188)\end{array}$ & $\begin{array}{r}-0,0004247 \\
(0,000019)\end{array}$ & $\begin{array}{l}-0,0003486 \\
(0,0000149)\end{array}$ & $\begin{array}{c}-0,000346 \\
(0,0000149)\end{array}$ \\
\hline Norte & & & & & $\begin{array}{c}0,3179177 \\
(0,0107651)\end{array}$ & $\begin{array}{l}0,3135879 \\
(0,010853)\end{array}$ & $\begin{array}{c}0,3075794 \\
(0,0083577)\end{array}$ & $\begin{array}{c}0,3068224 \\
(0,0083386)\end{array}$ \\
\hline Centro-Oeste & & & & & $\begin{array}{c}0,4333422 \\
(0,0106651)\end{array}$ & $\begin{array}{c}0,4362985 \\
(0,0107517)\end{array}$ & $\begin{array}{l}0,4223956 \\
(0,0082755)\end{array}$ & $\begin{array}{c}0,4217045 \\
(0,0082565)\end{array}$ \\
\hline Sul & & & & & $\begin{array}{c}0,3627153 \\
(0,0086766)\end{array}$ & $\begin{array}{c}0,3670941 \\
(0,0087759)\end{array}$ & $\begin{array}{c}0,3852664 \\
(0,0067716)\end{array}$ & $\begin{array}{c}0,3834234 \\
(0,0067565)\end{array}$ \\
\hline Sudeste & & & & & $\begin{array}{c}0,3805723 \\
(0,0066823)\end{array}$ & $\begin{array}{c}0,3846862 \\
(0,0067876)\end{array}$ & $\begin{array}{c}0,4034758 \\
(0,0052436)\end{array}$ & $\begin{array}{c}0,4024554 \\
(0,0052319)\end{array}$ \\
\hline $\begin{array}{l}\text { Residência } \\
\text { urbana }\end{array}$ & & & & & $\begin{array}{l}0,2861654 \\
(0,0077118\end{array}$ & $\begin{array}{c}0,1948708 \\
(0,0089023)\end{array}$ & $\begin{array}{c}0,1469646 \\
(0,0069862)\end{array}$ & $\begin{array}{c}0,1454956 \\
(0,0069676)\end{array}$ \\
\hline Migrante & & & & & $\begin{array}{c}0,1084317 \\
(0,0052626)\end{array}$ & $\begin{array}{c}0,1098252 \\
(0,0053107)\end{array}$ & $\begin{array}{c}0,0942554 \\
(0,00409)\end{array}$ & $\begin{array}{c}0,0940008 \\
(0,0040811)\end{array}$ \\
\hline Setor público & & & & & & $\begin{array}{c}0,0723894 \\
(0,0117723)\end{array}$ & $\begin{array}{c}0,1439959 \\
(0,0093008)\end{array}$ & $\begin{array}{c}0,1367151 \\
(0,0092758)\end{array}$ \\
\hline $\begin{array}{l}\text { Indústria } \\
\text { extrativa }\end{array}$ & & & & & & $\begin{array}{l}-0,0605635 \\
(0,0114744)\end{array}$ & $\begin{array}{c}0,0239481 \\
(0,0122029)\end{array}$ & $\begin{array}{c}0,2319894 \\
(0,0124537)\end{array}$ \\
\hline $\begin{array}{l}\text { Indústria de } \\
\text { transformação }\end{array}$ & & & & & & $\begin{array}{c}0,1224891 \\
(0,0089692)\end{array}$ & $\begin{array}{c}0,065991 \\
(0,0086318)\end{array}$ & $\begin{array}{l}0,0183383 \\
(0,008868)\end{array}$ \\
\hline
\end{tabular}




\begin{tabular}{|c|c|c|c|c|c|c|c|c|}
\hline Variáveis & Modelo 1 & Modelo 2 & Modelo 3 & Modelo 4 & Modelo 5 & Modelo 6 & Modelo 7 & Modelo 8 \\
\hline $\begin{array}{l}\text { Serviços } \\
\text { produtivos }\end{array}$ & & & & & & $\begin{array}{c}0,2676099 \\
(0,0117264)\end{array}$ & $\begin{array}{c}0,1584681 \\
(0,0104164)\end{array}$ & $\begin{array}{c}0,1246819 \\
(0,01051)\end{array}$ \\
\hline $\begin{array}{l}\text { Serviços de } \\
\text { distribuição }\end{array}$ & & & & & & $\begin{array}{c}0,193485 \\
(0,0087717)\end{array}$ & $\begin{array}{l}0,0887609 \\
(0,008383)\end{array}$ & $\begin{array}{c}0,0506135 \\
(0,0085418)\end{array}$ \\
\hline $\begin{array}{l}\text { Serviços } \\
\text { Sociais }\end{array}$ & & & & & & $\begin{array}{c}0,1732808 \\
(0,0123076)\end{array}$ & $\begin{array}{c}0,04623 \\
(0,011031)\end{array}$ & $\begin{array}{c}0,0436482 \\
(0,0110085)\end{array}$ \\
\hline Capitalista & & & & & & & $\begin{array}{c}1,789378 \\
(0,0270939)\end{array}$ & $\begin{array}{c}1,789099 \\
(0,027032)\end{array}$ \\
\hline $\begin{array}{l}\text { Pequeno } \\
\text { empregador }\end{array}$ & & & & & & & $\begin{array}{c}1,136073 \\
(0,0124932)\end{array}$ & $\begin{array}{c}1,136625 \\
(0,0124673)\end{array}$ \\
\hline $\begin{array}{l}\text { Autônomo } \\
\text { com ativos }\end{array}$ & & & & & & & $\begin{array}{l}0,5334673 \\
(0,010979)\end{array}$ & $\begin{array}{c}0,5408964 \\
(0,0109648)\end{array}$ \\
\hline $\begin{array}{l}\text { Autônomo } \\
\text { agrícola }\end{array}$ & & & & & & & $\begin{array}{l}-0,0140359 \\
(0,0117339)\end{array}$ & $\begin{array}{c}-0,0144826 \\
(0,0117033)\end{array}$ \\
\hline $\begin{array}{l}\text { Especialista } \\
\text { autônomo }\end{array}$ & & & & & & & $\begin{array}{c}1,115491 \\
(0,0223685)\end{array}$ & $\begin{array}{c}1,119436 \\
(0,0223123)\end{array}$ \\
\hline Gerente & & & & & & & $\begin{array}{c}0,9464578 \\
(0,0144185)\end{array}$ & $\begin{array}{c}0,9519983 \\
(0,0143842)\end{array}$ \\
\hline Especialista & & & & & & & $\begin{array}{c}0,9418829 \\
(0,0144317)\end{array}$ & $\begin{array}{c}0,9419349 \\
(0,0143927)\end{array}$ \\
\hline Qualificado & & & & & & & $\begin{array}{c}0,5058554 \\
(0,0108486)\end{array}$ & $\begin{array}{c}0,5232658 \\
(0,0108696)\end{array}$ \\
\hline Supervisor & & & & & & & $\begin{array}{c}0,5342563 \\
(0,0163557)\end{array}$ & $\begin{array}{c}0,5242498 \\
(0,0163258)\end{array}$ \\
\hline Trabalhador & & & & & & & $\begin{array}{c}0,262271 \\
(0,0080076)\end{array}$ & $\begin{array}{c}0,2742707 \\
(0,0080215)\end{array}$ \\
\hline $\begin{array}{l}\text { Autônomo } \\
\text { precário }\end{array}$ & & & & & & & $\begin{array}{c}0,0646534 \\
(0,0098813)\end{array}$ & $\begin{array}{c}0,0806644 \\
(0,0099046)\end{array}$ \\
\hline $\begin{array}{l}\text { Emprego } \\
\text { doméstico }\end{array}$ & & & & & & & $\begin{array}{l}0,0364307 \\
(0,012463)\end{array}$ & $\begin{array}{c}0,1035388 \\
(0,0128106)\end{array}$ \\
\hline $\begin{array}{l}\text { Composição } \\
\text { de gênero } \\
\text { ocupações }\end{array}$ & & & & & & & & $\begin{array}{c}-0,2155389 \\
(0,00978)\end{array}$ \\
\hline Estatística BIC & -1818192 & -1871691 & -1871691 & -1883522 & -1889802 & -1891103 & -1904567 & -1904856 \\
\hline
\end{tabular}

Nota: Coeficientes estimados com erros padrões (entre parênteses). Estatística Z.

Fonte (dados originais): IBGE, Microdados da PNAD de 2005. 
Tabela 2-A

Coeficientes Estimados da Vantagem de Renda do Homem entre os Não Brancos, de acordo com Diferentes Modelos Lineares Generalizados

\begin{tabular}{lcc}
\hline Modelos & Distância entre não brancos & Termo interativo \\
\hline Modelo 1 & 0,3252773 & 0,053115 \\
& $(0,0113938)$ & $(0,01564)$ \\
\hline Modelo 2 & 0,2520464 & 0,0681164 \\
& $(0,0115437)$ & $(0,0155498)$ \\
\hline Modelo 3 & 0,3671178 & 0,0940038 \\
& $(0,0089071)$ & $(0,0119492)$ \\
\hline Modelo 4 & 0,3190047 & 0,0718759 \\
& $(0,0078142)$ & $(0,0104712)$ \\
\hline Modelo 5 & 0,3523632 & 0,0560688 \\
& $(0,0077518)$ & $(0,0103553)$ \\
\hline Modelo 6 & 0,3344804 & 0,0642068 \\
& $(0,0082679)$ & $(0,0104866)$ \\
\hline Modelo 7 & 0,3344804 & 0,0484684 \\
& $(0,0082679)$ & $(0,0080944)$ \\
\hline Modelo 8 & 0,2136437 & 0,0535507 \\
& $(0,0071171)$ & $(0,0080793)$ \\
\hline
\end{tabular}

Notas: Coeficientes estimados com erros padrões (entre parênteses). Estatística Z. Como foi feita apenas a recodificação da variável binária raça, para efeito de estimativa da distância (gap) de rendimentos entre os não brancos, não são apresentados os demais coeficientes.

Fonte (dados originais): IBGE, Microdados da PNAD de 2005. 


\section{A INTERAÇÃO ESTRUTURAL ENTRE A DESIGUALDADE DE RAÇA E DE GÊNERO NO BRASIL}

\section{José Alcides Figueiredo Santos}

Palavras-chave: Divisões sociais; Desigualdade de gênero e raça; Interseções entre classe, raça e gênero; Rendimentos.

Este trabalho é orientado pela noção teórica de que as divisões sociais geram efeitos derivados da sua interação estrutural. Tendo em mente esta motivação teórica, o autor estima a distância de gênero de renda entre os grupos branco e não branco (pretos e pardos) no Brasil. Todos os oito Modelos Lineares Generalizados estimados, cujas variáveis são sucessivamente incluídas, mostram que a distância de gênero é grande em ambos os grupos raciais, porém é ainda maior entre os brancos. A investigação explora o papel do contexto subjacente da desigualdade de classe, assim como de outros fatores, no entendimento da variação racial da desigualdade de gênero. Considera-se que as características da desigualdade racial no Brasil, assim como as interseções entre classe e raça, explicam esta maior vantagem de gênero do homem branco. A hierarquia racial estabelece certo limite de variação sobre a hierarquia de gênero no grupo não branco.

\section{STRUCTURAL INTERACTION BETWEEN GENDER AND RACE INEQUALITY IN BRAZIL}

\section{José Alcides Figueiredo Santos}

Keywords: Social divisions; Gender inequality; Racial inequality; Intersections between class, race and gender; Ernings.

This paper is guided by the theoretical notion that social divisions generate effects derived from its structural interaction. Having in mind this theoretical motivation, it estimates the gender earnings gap among white e non white (black and mixed color) groups in Brazil. All the eight Generalized Linear Models estimated, whose variables are successively included, show that the gender gap is big across both racial groups but it is bigger among whites. The investigation explores the role of the underlying context of class inequality, as well as others factors, on understanding the racial variation of the gender inequality. The study considers that the characteristics of the racial inequality in Brazil, as well as the intersection between class and race, explain the bigger gender advantage for the white man. The racial hierarchy establishes limits of variation on the gender hierarchy for the non white.

\section{L'INTERACTION \\ STRUCTURELLE ENTRE L'INÉGALITÉ DE RACE ET DE GENRE AU BRÉSIL}

\section{José Alcides Figueiredo Santos}

Mots-clés: Divisions sociales; Inégalité de genre et de race; Intersections entre classe, race et genre; Revenus.

Ce travail est guidé par la notion théorique suivant laquelle les divisions sociales gèrent des effets dérivés de leur interaction structurelle. Ayant cette motivation théorique en vue, l'auteur estime la distance de genre de revenu entre les groupes blanc et non-blanc (noirs et métis) au Brésil. Tous les huit Modèles Linéaires Généralisés estimés, dont les variables sont succéssivement inclues, démontrent que la distance de genre est grande dans les deux groupes raciaux, mais l'est davantage entre les blancs. La recherche explore le rôle du contexte sous-jacent de l'inégalité de classe, ainsi que les autres facteurs, suivant la compréhension de la variation raciale de l'inégalité de genre. Nous considérons que les caractéristiques de l'inégalité raciale au Brésil, ainsi que les intersections entre classe et race, expliquent cet avantage accru de genre de l'homme blanc. La hierarchie raciale établit une certaine limite de variation sur la hiérarchie de genre dans le groupe nonblanc. 